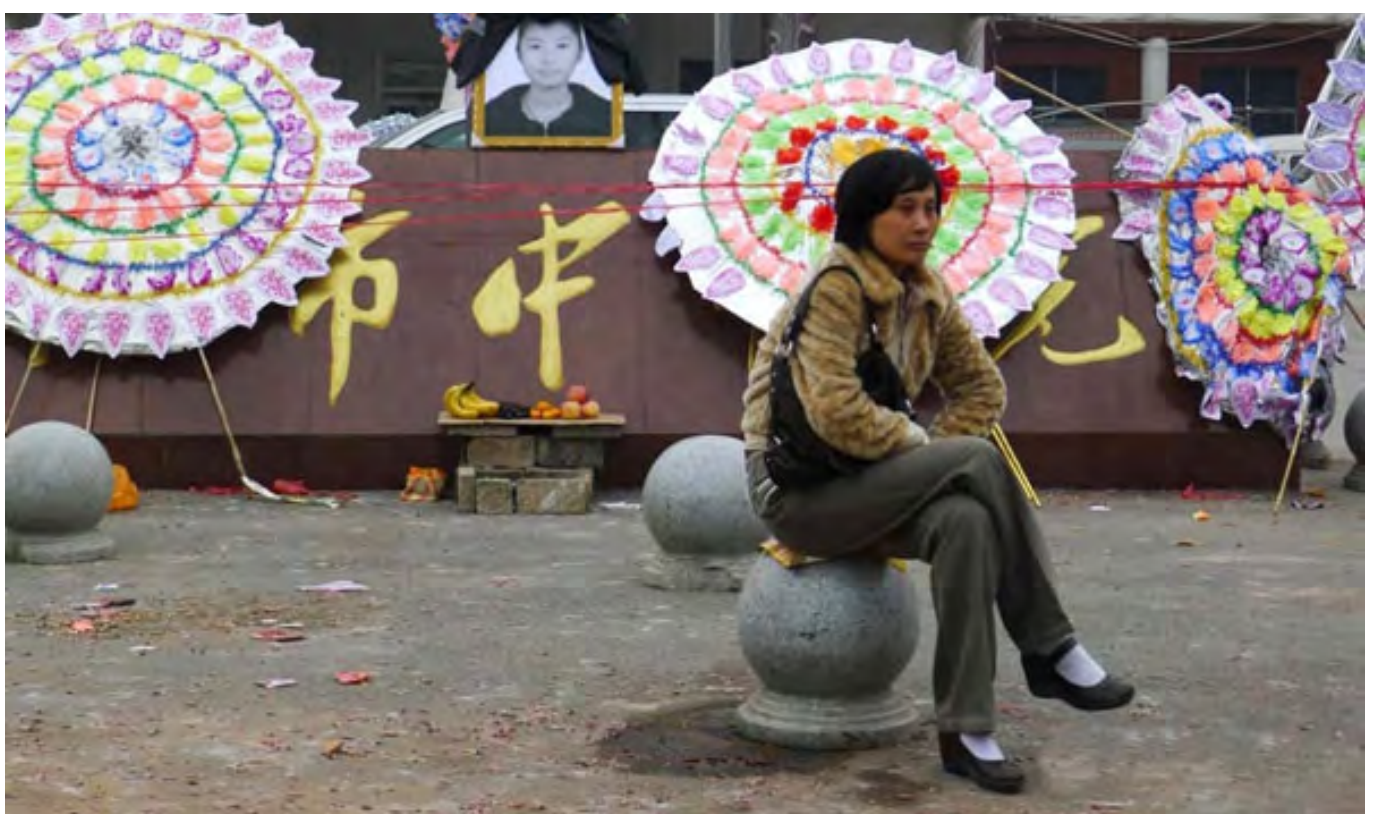

\title{
Medical
}

PC: Chinavalue.net.

\section{Disturbances as}

\section{a Form of Patient}

\section{Xiao TAN}

\section{Tianyang LIU}

In China, patients, their relatives, or organised groups sometimes resort to 'medical disturbances' (医闹, yi nao) as a way of expressing grievances. Drawing on existing scholarly accounts and our recent research, this essay provides reflections on this phenomenon through the lens of patient activism.

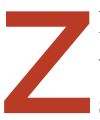
hang Meimei, a singer aged in her thirties, underwent two plastic surgeries at the Shenzhen Peng'ai Hospital in 2017. Unsatisfied with the outcome, she asked the hospital for compensation of 1.2 million yuan. After payment was refused and a series of disputes, on 14 July 2020, she led several people in a protest in front of the building, carrying placards showing photos of her unsuccessful surgery and various slogans, including: 'Shenzhen Peng'ai Hospital is blackhearted', 'Shenzhen Peng'ai Hospital inflicts 
much suffering', and 'Return justice to me, Shenzhen Peng'ai Hospital!'. The protest attracted significant publicity on the crowded street; the hospital reported the protest to the police and accused Zhang Meimei of creating a 'medical disturbance' (医闹, yi nao) (Xiang 2020).

In China, the term yi nao was officially adopted in 2006, when the Ministry of Health made its first official statement on what the media described as an 'yi nao incident' (医闹事 件) in Yunnan Province: a group of unemployed people had organised a disturbance in a hospital to obtain compensation for medical malpractice (Ministry of Health 2006; D. Wang 2015). The term has since been commonly used to refer to a form of disturbance that involves symbolic actions taken in hospitals, such as gatherings, sit-ins, public displays of crying, cursing medical staff, raising banners, displaying patients' corpses, establishing funeral shrines, or blocking entrances (Liu and Tan 2020). The phenomenon of yi nao has attracted wide attention in Chinese society and has been discussed often in the annual Two Sessions (the meetings of China's top legislature and top political advisory body), where only major issues are discussed (Chang 2020).

\section{The Logic of Yi Nao}

In scholarly analyses, yi nao has frequently been attributed to various structural problems within the Chinese healthcare system. Cuts to state subsidies have forced hospitals to seek other sources of financing, and newly imposed pricing structures have incentivised hospitals to sell medicines and technologybased services to subsidise their losses. Consequently, the overprescription of drugs and unnecessary diagnostic tests has become prevalent, leading to widespread discontent with unfairly high prices (Blumenthal and Hsiao 2015). The quality of services in Chinese hospitals is frequently perceived to be problematic (Hesketh et al. 2012). Treatment is seen as rushed, impersonal, and disrespectful (D. Wang 2015). Despite continuous efforts at health reform in the past decade, patients' satisfaction with clinical services remains low (Yip et al. 2019).

However, in the event of patient dissatisfaction, limited options for recourse are available and the existing channels are seen as biased (Hu and Zeng 2015; Pan et al. 2015; Zhang and Cai 2018). These structural problems have led some to adopt and justify $y i$ nao as a way of protecting their rights when they believe they have been mistreated (there have also been cases driven entirely by economic interests). While some initiate yi nao with the help of their relatives and friends, organised groups will also stage a medical disturbance in exchange for money (S. Wang 2015).

In recent years, yi nao has been increasingly interpreted as a phenomenon that plays on the stability-maintenance (维稳) mentality of the government and hospital management (Luan and Meng 2012; Xiao 2016; Liu and Tan 2020). In China, stability maintenance is a top priority and involves a set of interrelated strategies, measures, and ideologies that aim to maintain the rule of the Chinese Communist Party and prevent any social disturbances (ranging from mass incidents to small-scale, lesscontroversial civic disturbances) that might threaten the status quo and the legitimacy of the ruling regime (Benney 2016; Xie and Liu 2019).

Despite the privatisation of financing since the 1980s, public hospitals remain closely tied to the government as their presidents are still appointed by the government and, as government cadres, are required to act in accordance with the core values and political agenda of the Party-State (Allen et al. 2014). They tend to adopt the same stabilitymaintenance mentality-prioritising social stability in decision-making, reflecting both the stability-oriented political structure and individual officials' behavioural and ideological preferences. During yi nao incidents, public hospital management and local governments 
try to avoid any disruption to social stability. Therefore, they may choose to provide compensation as a pragmatic solution to appease the actors involved, which further incentivises people to resort to this type of action when discontent arises.

\section{Yi Nao as a Form of Patient Activism?}

In the academic literature on civic engagement and popular politics in China, patient activism has been largely overlooked. Activism refers to individual or group readiness to engage in legal and nonviolent protest (Moskalenko and McCauley 2009). Essentially, many of those involved in yi nao protests are demanding justice-in particular, from a healthcare system that is perceived as problematic and unfair, with an economically driven prevalence of overprescription, rushed and impersonal services, and an underdeveloped system of recourse. However, the agendas of yi nao actors are not always clear and consistent. These disturbances may be initiated by patients to defend their rights, but may also be exploited by organised groups, sometimes including gang members, to maximise their own profit. Yi nao frequently involves a series of publicity-attracting elements, with forms of performativity at their core to amplify the desired effect on the audience. Despite the 'performative' quality, yi nao cases can also be escalated and become violent, especially when carried out by organised groups. Crucially, while yi nao protestors usually frame their activities as an apolitical expression of discontent over unfair treatment, they may advance to perform types of public disruption that can be perceived as explicitly threatening social stability, thus transforming these actions into a political challenge.

Relatedly, yi nao is a manifestation of 'activist citizens', who differ from 'active citizens' in that they do not follow institutionalised rules of civic participation, but subversively disrupt rules and routines within institutionalised contexts by transforming them into new sites of struggle (Isin 2008: 39). In other words, the creation of counterspaces through yi nao within institutionalised venues can be understood as a rupture in and interruption to the institutional makeup of society that render visible and audible new sites of claim-making. For example, $y i$ nao's creation of counterspaces usually involves highly visible and noisy intrusions into administratively controlled places in hospitals, such as by placing coffins and corpses in entry and reception areas, burning paper money, playing folk funeral songs, or raising banners. Disobedience through the production of counterspaces, therefore, is exploited to render the patient's voice audible and make visible in the public sphere the perceived 'wrongs' they address. The radical nature of their actions also shifts the scale of visibility of the patient body politic, making their grievances a news story in the mainstream media.

However, yi nao is much less ambitious in its goals. The ultimate demand is typically economic compensation, rather than comprehensive reform of the healthcare system that would better promote justice and protect patients' rights. Essentially, yi nao actors navigate their own concerns and needs and those of the government while capitalising on the political sensitivity of stability maintenance to fulfil their economic interests. That the regime is not especially threatened by $y i$ nao is also evident in the fact that police are relatively tolerant of such incidents. In our review of cases of medical disturbances between the end of 2013 and the end of 2018 , hospitals generally reported such situations to local police; however, it was only when actions became serious and violent that the police intervened (Liu and Tan 2020).

To some extent, it was exactly this relatively 'benign' approach by the authorities that led wronged patients to look on the government as their protector and provided a space for the emergence of yi nao. The government has tended to be more tolerant of yi nao actors 
than of participants in other forms of social activism. In our study, we found that the leaders of such incidents were most likely to be given short-term administrative detention, ranging from one to two weeks, and only occasionally criminal detention for several months or years. There were frequently no consequences for those involved in yi nao other than the organisers.

\section{What's Next?}

Similar to the situation in many other areas, in recent years, the government's tolerance of $y i$ nao has been shrinking. In the Amendment IX to the Criminal Law of the People's Republic of China in 2015, gatherings designed to disrupt the normal order of medical settings were defined as illegal. In July 2016, the National Health and Family Planning Commission, along with eight other state ministries, launched a one-year special hard-strike campaign to crack down on medical disturbances. On completion of the campaign, the commission and other government bodies issued new measures to maintain the normal order of medical settings and punish yi nao actors (National Development and Reform Commission 2018; National Health Commission of China 2017). Significantly, the National People's Congress approved the Law on the Promotion of Basic Medical and Health Care in 2019, which further bans any organisation or individual from threatening or harming the personal safety or dignity of health workers. Following these central government policies, local governments have also taken a less tolerant approach and the police have become more actively engaged in recent yi nao cases.

In fact, there has been much less news coverage of $y i$ nao cases than in the past, either due to the waning of this phenomenon or because of increasingly strict censorship. Initially, yi nao's apolitical goals and strategies playing on the stability-maintenance mentality of governments and hospitals created a space for such protest. However, the involvement of radical and violent elements has contributed to $y i$ nao being interpreted as a crime. With the more proactive recent approach of the Chinese Government, medical disturbances may be becoming a thing of the past.

This research was supported by China's National Social Science Foundation, Youth Project (20CZZO14). 
This text is taken from Made in China Journal: Volume 5, Issue 3, 2020, edited by Ivan Franceschini and Nicholas Loubere, published 2021 by ANU Press, The Australian National University, Canberra, Australia.

doi.org/10.22459/MIC.05.03.2020.02 